\title{
The Influence of Internet and New Media on Teenagers' Ideological and Moral Construction
}

\author{
Jie Yang \\ Chengdu Agricultural College \\ Chengdu, China
}

\begin{abstract}
The arrival of the era of Internet and new media acceleration has brought the Internet and new media into every corner of human society. It has also spawned a new media network culture, which has been greatly favored among adolescents, and has had a very significant impact on the ideological and moral construction of adolescents. This era has quickly led the lives of the masses, living the Internet and new media in life, and has had an impact on the ideological and moral construction of adolescents. It broadens the living environment of human beings and provides a new media platform for the development of adolescents' ideological and moral construction.
\end{abstract}

Keywords-Internet; new media; youth; ideological and moral construction

\section{INTRODUCTION}

At first, the Internet was only a medium for disseminating small spatial information. It has developed and spread in the era, and it has rapidly grown into a new medium with powerful functions for disseminating information. It has quickly merged with the times and has become a special symbol of the era - the Internet age. The new era of the Internet and new media has swept into the public's life, and has spawned a new media network culture. With its dual influence, it has quickly entered the shaping of adolescents' values and its ideological and moral construction, and has brought particularly remarkable effects, which fully reflects the current situation of networking and networking of adolescents' thoughts.

\section{BASIC CONCEPT}

The most popular definition of the Internet is to cover the whole world, and it is a huge network in which the network and the network are connected to each other. New media is a comparatively relative concept. It is a new media form developed through new media by traditional media, such as newspapers, radio, magazines, etc. The Internet and new media are digital new media that traditional media send signals and disseminate information to people through electronic terminals. The integration and transformation of the Internet and new media is accelerating the formation of a stronger new cultural form and forming a trend pattern. The current forms of traditional education, ideological and moral construction, etc., are facing the challenges and opportunities of this platform innovation.

\section{BASIC FEATURES}

\section{A. Characteristics of the Internet and New Media}

1) Diversification: The Internet and new media have made the lives of the public networked. The network is everywhere in people's society. The Internet and new media have replaced the boring and unitary nature of traditional media, providing a variety of online content and forms. The public can learn about the most cutting-edge dynamics around the world through the Internet, bringing a lot of fun and motivation to life and learning. Such platforms as Weibo, WeChat, blog, Internet TV, Mei Pai, Miao Pai, Xiaokaxiu and post bar, etc., enrich the real online life of teenagers.

2) Fragmentation: Although the Internet and new media provide many styles and rich online life for the public, because the Internet and new media are open, the wideness of their channels, the replacement of platforms, and the diversity of content make the network information much more massive and fragmented, which greatly reduces the attention and usefulness of the information, and instead generates a lot of information garbage. Much of the information appears vulgar and worthless, and much useful and valuable information is quickly overwhelmed. This means that the ideological and moral construction information under the Internet and the new media is rapidly fragmented, unfocused, and non-directional.

3) Entertainment: The rapid development of society has also accelerated the pace and rhythm of people's lives. Various employment and academic pressures have followed. The existence of the Internet and new media is like a kind of leisure agent, which brings more fun to the boring and tedious daily life. TV dramas, movies, music, games and other activities have also provided better channels for people to vent their pressure. However, the top search and headlines on the Internet are all stars' entertainment news, and the moral education content that the society is in need, as well as the domestic and international news that people should know, accounts for only a small part, and it wouldn't be the first choice of people.

4) Negative: The basic characteristics of Internet new media are highlighted by the openness and anonymity. This 
makes the social news of the vulgar and violent, mostly in addition to a large number of star entertainment news, which not only seriously threatens the order of the society, but also pollutes the civilization of the society more quickly. This has become a great obstacle and challenge for the ideological and moral construction of adolescents. The induction of worse and worse information makes adolescents feel less about collectivism. Instead, they tend to pursue so-called individuality and freedom. It is easy to induce egoism, money worship and hedonism.

\section{B. Characteristics of Ideological and Moral Construction of Adolescents}

1) Personalization: Adolescents are distinctive in their characteristics and eager to be recognized. In the era of new Internet media, adolescents' personality is more prominent. They have strong sense of truth-seeking, strong interest in participation, good at innovation, and they are more active, open and lively in expressing their feelings or opinions. Adolescents have relatively stable self-concepts and selfimages. They have lofty ideals and ambitions. They use a more abstract, complex and unique way to understand the world and understand society, but at the same time they need the promotion and guidance of external forces. This period is the best time to accept ideological and moral education and cultivate ideological and moral culture.

2) Irrationality: The entire outlook on life, world outlook and values of adolescents are not yet stable. They need to be adjusted. Their physiological and psychological development is not mature enough, and their ability to distinguish themselves is weak. This makes the adolescents extremely vulnerable to the bad atmosphere and bad public opinion in the Internet and new media. As far as ideological and moral construction is concerned, the bad information disseminated by the media platform has a great influence on the decline of adolescents' ideological and moral awareness, and may even weaken the sense of responsibility of adolescents. There are also some phenomena of spiritual emptiness and misconduct.

3) Curiosity: Adolescents have simple thoughts, and they are curious about the unknown. They have weak selfprotection, and they are sensitive to the surrounding reality and online life. The all-encompassing network information just caters to the aspiration to knowledge and curiosity of adolescents, and it has a huge charm and appeal. Adolescents have a shallow experience, and their concept of right and wrong is not clear enough. They lack mature ideological and moral cultivation. They are more exclusive to traditional education and tend to find fun in all kinds of online information to satisfy their curiosity.

\section{THE DUALITY OF THE INFLUENCE OF THE INTERNET AND NEW MEDIA ON THE IDEOLOGICAL AND MORAL CONSTRUCTION OF ADOLESCENTS}

The Internet culture of the Internet and new media is a double-edged sword. The content is rich and varied but the quality is different. The closeness of the network and life makes it have a dual impact on the ideological and moral construction of adolescents.

\section{A. Positive Impact}

First of all, the advent of the Internet and new media has made the Chinese Communist Party's line, guidelines, and policies more favorable, and provides a new platform for cultivating the "Four Haves" youth. Almost everyone now lives with the Internet, and life cannot be separated from the Internet. Therefore, a large number of advanced personal deeds of the platform and various party policies can be spread through the form of online mobile newspapers, that is, it not only gets rid of the boring reading of newspapers, but also can arouse the interest of adolescents. With the joint efforts of the government and the public, the positive online culture is becoming the main theme.

Secondly, this is a favorable platform for adolescents to obtain information, to know the world, to reach out to the society, to broaden their horizons, and to promote the promotion of moral education. And it promotes the dissemination and sharing of various knowledge and information. There is a greater advantage and convenience for adolescents to know the world and broaden their thinking. The Internet and new media are not only important channels for accessing all kinds of information, but more importantly, they provide a platform for people to participate in the dissemination and utilization of information. It fully embodies the synergy of interaction and provides a broader learning space for the ideological and moral construction of adolescents. Internet and new media information is extremely large in content, rich in content, involving various terminology, as well as ideological and moral construction, current politics, and the transmission of various types of information, which are changing and accelerating the transformation of the educational structure of the entire society.

\section{B. Negative Impact}

First of all, the negative energy and vulgar news in the Internet and new media have made the educational input of adolescents' ideological and moral construction a great obstacle. Because adolescents are in an immature period, their thoughts and emotions are in an irrational state, their self-control ability is weak, and the influence of negative news will make them easy to be impulsive when dealing with factual problems, thus making the wrong choice. In particular, the wide channel on the Internet, violent pornography and the bad induction of red-level marketing accounts of various networks will shake adolescents' ideological and moral concepts and correct outlook on life and values, which poses a great challenge to the ideological and moral construction of adolescents.

Secondly, the overheating trend of negative energy values such as online hot words tends to make adolescents fall into misunderstanding of traditional education. Traditional education is experienced and learned by adolescents from small to large. It is inconvenient for a single infusion form, and many network hot phenomena are 
staged, diverse in content and diverse in form, such as many online hot words especially favored by teenagers. It is precisely because of their curiosity and follow-up mentality that these moral bottom lines are too popular, which makes the ideological and moral construction of adolescents face enormous obstacles and challenges.

Again, due to too much concentration on online life, nowadays, more teenagers lack physical exercise and lack of social communication, which is not conducive to the healthy development of their physiological psychology. On the one hand, the Internet and new media have narrowed the distance between people. People from all over the world can talk to each other through media terminals, express their emotions and choose friends. On the other hand, it has distanced people from people. In real life, people are addicted to the Internet and neglect the relatives and friends around them, which make the public's interpersonal relationship indifferent. In particular, it weakens the ability of adolescents to communicate in real life, both emotionally and behaviorally. Over time, adolescents will become indifferent, selfish, and even ruthless. Adolescents, as the successors of the country's future, are not conducive to the vigorous development of the socialist countries.

\section{The Way to Apply INTERnEt NeW Media to PROMOTE YOUTH IDEOLOGICAL AND MORAL CONSTRUCTION}

\section{A. Satisfying and Leading the User's Needs}

The reason why the public is more repulsive of some positive energy news is due to the formal serious and boring content. In the life, people use the Internet for enjoyment. Of course, they will subconsciously reject the content of positive propaganda. Therefore, it is necessary to properly grasp the degree between formal content and relaxed form. The reason why the Internet and new media can be sought after by the public is because it is not a unilateral export of its information, but a medium that can be shared and used. To reflect the advantages of network culture, it is necessary to constantly meet the needs of users, close to the masses, seek truth from facts, and more reflect the leisure of life. The most important thing is that ideological and moral construction should make the Internet new media become its new classroom and promote the formation of open ideological and moral construction.

\section{B. Purifying and Coloring Educational Content}

Purifying content not only requires official guidance, but also requires a strong legal system for supervision. Promoting excellent network culture and spreading the party's principles and policies can gradually form a unified national culture, and shape the network quality civilization to realize its own value. Especially for adolescents, subtle influence is the most fundamental way to truly carry out ideological and moral construction. Adolescents often choose to browse objects in an easy and free method and mentality. This requires the object content to show its own color. That is to say, the characteristics of adolescents need the vividness and flexibility of ideological and moral construction content, thus promoting the all-round development of adolescents to cultivate the patriotism spirit of adolescents and achieve the goal of ideological and moral construction.

\section{Innovating and Enriching the Form of Net Text}

In addition to rich and colorful content, the novel and unique net text form is one of the reasons why teenagers especially love online culture. Since adolescents are attracted to the Internet, the key to ensuring the youth's stickiness lies in the right counterparts, that is, the entertainment forms and visual impressions in which the Internet and new media are interspersed. Therefore, especially the content of political construction and ideological and moral construction, due to boring and official colors, will be often rejected by rebellious adolescents. Just like the integration and transformation of traditional media and the Internet, it is the same as the winwin new media era. The traditional culture and the ideological and moral construction of adolescents can only be promoted by the compatibility of the Internet and new media, that is, they can reflect their correct values and seize the diverse forms of new media for easy entertainment. It is not only in the form of serious articles, or letting adolescents memorize moral principles, but also creating different opportunities for them to accept and comprehend these norms in order to win the warm general ideological and moral cultivation environment.

\section{CONCLUSION}

The Internet culture of the Internet and new media not only brings about all aspects of the changes in people's lives, but also changes all aspects of people's lives. Of course, society is developing. It is necessary to adjust the balance between the network and life in a timely manner, so that the advantages of the network outweigh the disadvantages. With the help of the new Internet media platform, it will be of necessity to actively spread and adhere to the Xi Jinping series of thoughts, Marxism, Mao Zedong Thought, Deng Xiaoping Theory and the main thinking of the "Three Represents", carry forward and develop excellent Chinese traditional culture and fine traditional virtues, promote the ideological and moral construction of adolescents and vigorously promote the building of socialist spiritual civilization. Through the lively and easy Internet new media platform, the fun and attention of adolescents will be enhanced by the enjoyment of healthy and relaxed ethical and cultural resources. Therefore, it is very important to avoid the negative of the network and to disseminate positive information.

The Internet and new media should be inclined to the propaganda of ideological and moral construction, create a correct public opinion of moral values, values, and outlook on life, purify the media network, and guide adolescents to improve their self-identification ability. In general, in recent years, the state has introduced a number of policies to purify the network public opinion. It not only has targeted countermeasures for some inferior artists, but also has a certain regulatory system for manufacturers of bad social networks, which makes the Internet and new media reflect. 
The excellent spiritual outlook of the Chinese nation has a certain platform effect, and it has also taken basic measures for the development of adolescents' ideological and moral construction. In the period of social transformation, the ideological and moral construction of citizens will inevitably face many puzzles and challenges. Therefore, it is necessary to reposition the content and function of ideological and moral education, and to improve and perfect its own input and output mode so that to provide a new media environment for adolescents with healthy, fun and beneficial spiritual food.

\section{REFERENCES}

[1] Li Zuchao, Xiang Feifei, Investigation and Analysis of the Status Quo of Youth Ideological and Moral Construction [J] School Party Building and Ideological Education, 2011, 06. (in Chinese)

[2] Chen Li, Qian Yunlou, Wang Linwan, The Influence of New Media on Teenagers' Ideological and Moral Education and the Countermeasures [J] Journal of Hunan University of Science and Engineering, 2015, 07, 36 (07). (in Chinese)

[3] Li Qian, Liu Jianji, The Influence of Network Culture on the Ideological and Moral Construction of Contemporary Youth Against the Background of "Internet +" [J] Southern Review, 2016 (02). (in Chinese)

[4] Wu Yuhui, Xie Xinzhou, The Impact of New Media Such as the Internet on Public Opinion [J] Contemporary Communications, 2013 (03). (in Chinese)

[5] Zhang Kaixiang, The Role of New Media in the Ideological and Moral Construction of adolescents [J] Ningxia Education, 2015 (05). (in Chinese)

[6] Yan Mingyu, The Negative Influence of Internet on Teenagers' Ideological and Moral Construction and Countermeasures [J] Qinghai Social Sciences, 2004 (05). (in Chinese) 